\title{
The VISIR+ Project-Helping Contextualize Math in an Engineering Course
}

\author{
Natércia Lima ${ }^{1,2}$, Marcelo Zannin ${ }^{3}$, Clara Viegas ${ }^{1,2}$, Arcelina Marques ${ }^{1,2}$; Gustavo Alves ${ }^{1,2}$, Manuel C. Felgueiras ${ }^{1,2}$, \\ Ricardo Costa ${ }^{1,2}$, André Fidalgo ${ }^{1,2}$, Juarez B. da Silva ${ }^{3}$, María I. Pozzo ${ }^{4}$, Elsa Dobboletta ${ }^{4}$, Ingvar Gustavsson ${ }^{5}$, \\ Francisco Garcia-Peñalvo ${ }^{6}$ \\ ${ }^{1}$ Research Centre in Industrial Technology and Engineering (CIETI), Portugal, ${ }^{2}$ School of Engineering - Polytechnic of Porto \\ (ISEP), Portugal, ${ }^{3}$ Federal University of Santa Catarina (UFSC), Brazil, ${ }^{4}$ National Council of Scientific and Technical Research \\ (CONICET), Argentina, ${ }^{5}$ Blekinge Institute of Technology, Sweden, ${ }^{6}$ Research Institute of Educational Sciences (IUCE), \\ University of Salamanca \\ nmm@isep.ipp.pt
}

\begin{abstract}
The long-term goal of engineering education is to prepare students to work as engineers. Being a practical profession, laboratories play a crucial role in illustrating concepts and principles as well as improving technical skills. In the last decades the use of online resources (simulators and remote labs) has been growing, either as a complementary and/or as an alternative way of developing experimental competences. In the scope of the VISIR+ Project, this work presents the first results of a didactical implementation using simultaneously the remote laboratory VISIR (Virtual Instrument Systems in Reality), simulation and calculus in a Math Course at the Federal University of Santa Catarina (UFSC). The preliminary results indicate that the use of several resources increases students' performance, boosting their learning and competence development.
\end{abstract}

Keywords - Remote Laboratory, VISIR, Computer Simulation, Competence Development, Learning and Teaching Strategies, Engineering Education

\section{INTRODUCTION}

Engineering higher education has undergone several innovations in the last decades, one of them being the use of Information and Communication Technology (ICT) tools. The use of virtual resources - remote labs and simulations - as a complementary and/or alternative learning tool to the traditional hands-on laboratories, allows students to develop experimental competences, which can play a different role in their importance for the engineering learning process [1], [2], [3]. Besides, the use of ICT tools may act as a stimulus for younger generations as they are digital natives [4]. Amongst these tools, one of the main instructional technologies adopted and valued in engineering education, are remote labs which are also, regarded as one of the major shifts in engineering education in the last 100 years [5].

The use of virtual resources presents several advantages: students can access the resources whenever, wherever and as many times they feel like, thus contributing to increase students' responsibility and autonomous work, supporting lifelong learning, etc. [3], [6], [7], [8]. Nevertheless, it is important for students to be aware that these resources provide different experimental results: well-behaved results from computational models for simulations and real experimental results for remote labs. Perhaps as a result of some intrinsic difficulties and availability of remote labs in certain domains, teachers are tending to use virtual resources more often, either substituting or complementing the traditional hands-on labs. Brinson [6] claims that a "blended" or "hybrid" approach to laboratory learning, that is a combination of hands-on labs and virtual labs, seems to be more effective than the use of just one of them. This is also supported by the conclusion that there is no significant difference in students' learning outcomes achievement in hands-on versus virtual labs [6]. However, virtual labs usage is still a step ahead from the didactic effort needed to maximize the potential of these tools.

The use of diversified methods, techniques and resources in education may allow teachers to reach more students, by helping them to overcome their difficulties more easily. It is believed that this is due to students' different learning styles [9], [10]. Still, more recently, some authors argue that learning styles are an urban legend in education and although there are individual differences amongst learners that should be considered, the emphasis should be on the characteristics they share. [11].

Teacher mediation in classroom also plays an important role in students' engagement in tasks [12]. In fact, there are some teacher mediation characteristics that foster it: giving authority to students and keeping the task challenging [13]. Still, from the beginning, the task should be clear to students - they must be aware of its purposes to know what they need to do to achieve an answer or solution.

This work describes how a teacher introduced virtual labs in a math course (calculus) in order to support students' visualization and experimentation of practical applications of differential equation solutions (in electrical circuits). This was an innovative approach since traditionally students start 
learning the mathematical tools and later use the same tools to study engineering problems. This work also intends to illustrate that with some degree of imagination and innovation, a remote lab like VISIR, based on electric circuits, may be used for experimental work in almost any engineering subject or application, regulated by differential equations. Therefore, a brief description of the VISIR system and VISIR+ Project aims are presented in section II and the didactical implementation in section III. Section IV describes the research design used in this course, and the results and discussion are presented in section $\mathrm{V}$, leading to some preliminary conclusions.

\section{VISIR}

\section{A. VISIR Remote Lab}

A remote laboratory is a real lab, where the user and the equipment are physically apart. The user is able to operate the remote equipment, configure and control the physical parameters of the experiment, through an internet access (computer, tablet or smartphone) and usually a particular user interface [14]. Amongst the most used laboratories in engineering education lies VISIR (Virtual Instrument Systems in Reality), launched on March 2004, by the Blekinge Institute of Technology (BTH) in Sweden. In fact, in 2015 it was considered the best remote controlled laboratory by the Executive Committee of Global Online Laboratory Consortium [15]. VISIR emulates a typical laboratory for conducting experiments in electric and electronic circuits - consisting on a remote workbench equipped with the same instruments, including a breadboard (Fig. 1), found in any hands-on lab [16]. At present, VISIR is installed in eight Higher Education Institutions (HEI) in six countries (Sweden, Austria, Spain, Portugal, Georgia and India) and has been used by thousands of students [17].

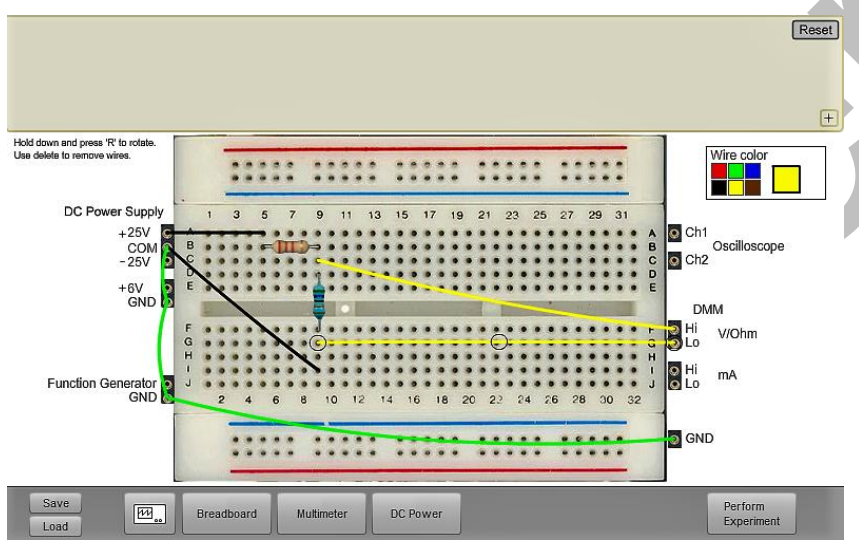

Fig. 1. Using VISIR

\section{B. The VISIR + Project}

In November 2015, five European Institutions (EU) VISIR+ Project EU partners - established a consortium with Brazil and Argentina to disseminate VISIR and spread its usage in these two Latin American (LA) countries - VISIR+ LA partners. EU partners are: the Blekinge Institute of Technology (BTH), School of Engineering of Polytechnic of Porto (ISEP), University of Deusto, the Spanish University for Distance Education (UNED) and Carinthia University of Applied Sciences (CUAS). LA partners are: Federal Institute of Education, Science and Technology of Santa Catarina (IFSC), Federal University of Santa Catarina (UFSC), Pontifical Catholic University of Rio de Janeiro (PUC), National University of Santiago del Estero (UNSE) and National University of Rosario (UNR).

VISIR+ Project aims to define and develop a set of educational modules comprising hands-on, virtual and VISIR remote lab, combined with calculus, following an enquirybased teaching and learning methodology, in electrical and electronic circuits' theory and practice.

Within VISIR+ Project, a VISIR system is being installed in five Latin American Institutions (LA partners), spreading its use within each institution and, also, within further associated secondary/professional/higher education institutions. The experience and expertise acquired by EU partners is being shared with LA partners. EU partners are providing technical and didactical support, thus playing the role of LA partners' tutors (roles are described in detail in the Project).

Prior to the didactical implementations which took place during the $2^{\text {nd }}$ semester of the 2016 academic year (one per LA partner), LA teachers had the opportunity to attend a Training Action (TA) at their own institution organised by each EU partner tutor. The purpose of the TA was to address teachers' needs, particularly to those implementing VISIR in their courses/classes.

\section{DIDACTICAL IMPLEMENTATION}

The didactical implementation of this study was performed in Federal University of Santa Catarina (UFSC), which is a public university in Brazil with about 5,500 technical, administrative and academic staff. It has roughly 30,000 students enrolled in 103 undergraduate programs and about 7,000 students enrolled in 133 graduate programs (academic master's, professional master's and doctoral degree). Its main campus is located in the state capital, Florianópolis, but it also has four other campuses distributed in the cities of Araranguá, Blumenau, Curitibanos and Joinville. It has more than 1,800 areas of research and several distance learning programs [18].

The chosen course was "Calculus IV", a $2^{\text {nd }}$ year, $2^{\text {nd }}$ semester course of two 5-year degrees, both in Araranguá, on:

- Computer Engineering ${ }^{1}$, (total 4,245 h)

- Energy Engineering ${ }^{2},($ total 3,600 h)

The course has 4 hours of lectures per week, during 18 weeks (72 hours), 36 students are enrolled in the course (90\% for the first time): 13 from Energy Engineering and 23 from Computer Engineering. It is important to state that this course teacher got to know VISIR and VISIR+ Project during the TA session. He

${ }^{1}$ structure.ufsc.br/2016/05/03/computer-engineering-ararangua/

${ }^{2}$ structure.ufsc.br/2016/05/03/energy-engineering-ararangua/ 
was quite enthusiastic and immediately interacted with EU partner tutor (ISEP) to explore the possibility of using VISIR complying with the didactic design considered in VISIR+ Project in his course. With his 5-year experience in teaching, he considers that students should visualize and try-out practical applications (electric and electronic circuits) of differential equations solutions, contextualizing the theoretical math concepts with the engineering applications.

The course content is rather theoretical and includes complex numbers, differential equations, Laplace transforms and Fourier transforms and series. The overall goal is that students get to know the mathematical functions and equations that are beneath typical physical phenomena.

VISIR has been used at least in 22 courses, covering more than 4400 students from different educational levels, different knowledge level and different type of implementations [19]. Still, all those courses dealt (at least partially) with electric and electronic circuits' analysis and electricity concepts. It is the first time that VISIR is implemented (along with simulation) in a theoretical Math Calculus course.

Following a summary of the teacher's plan for the curriculum where Learning Objectives and Resources were considered, Teacher Mediation and Students' Assessment are presented.

\section{A. Learning Objectives}

As previously stated, the overall course's goal is that students get to know the mathematical functions and equations that are beneath typical physical phenomena. With this implementation - using several resources (simulation and VISIR remote lab, together with calculus) the teacher wanted students to visualize and assemble electric and electronic circuits to relate the mathematical concepts to the electricity and electronics. As he was trying VISIR for the first time, he used it during two classes with a task covering about $20 \%$ of the courses' content. In fact, he introduced VISIR in the $3^{\text {rd }}$ week of the semester and the students were encouraged to use it autonomously since that time. He planned a task, in which students had to compare and understand the differences in the results obtained with calculus, VISIR and simulation, to be delivered in the beginning of the $10^{\text {th }}$ week - this way students had time to get familiarized with this new tool, available 24 hours a day/7 days per week. This task would also allow students to develop higher order skills such as critical analysis. These students already had physics courses with traditional hands-on labs in the previous semesters, but not the electricity courses (held only during the $3^{\text {rd }}$ year). Therefore, VISIR was their first experience with electrical circuits lab work.

\section{B. Resources}

Although this course only had lectures, the teacher used (although to a minor extent), the remote lab VISIR, CircuitLab simulator [20] and some graphical tools. In some classes, he used an enquiry-based teaching and learning methodology, trying as far as possible to give students time to complete the tasks by themselves. In the remaining classes teacher was more expositive.

To introduce VISIR, the teacher started by demonstrating assembling a circuit, trying to stimulate students' curiosity and motivation. In the following week, students tried the resource themselves (using their own computers), following teacher's instructions, but some had difficulties. Finally, the teacher prepared a tutorial 5-min video about VISIR, related to the circuit he wanted to explore, to get students more familiar with VISIR to use it autonomously. Teacher also established a course in a MOODLE (Modular Object-Oriented Dynamic Learning Environment) platform, where students could access all class materials, including the tutorial video introducing VISIR and the simulator. This also allowed students to interact with each other and with the teacher, posing questions and clarifying their queries.

\section{Teacher Mediation and Student Assessment}

Teacher advised students to develop autonomous work and encouraged them to work on their own with the several tools used in the course, including simulation and remote lab. He also made an effort to give immediate feedback to students work/progress.

Students were assessed by two individual written tests (respectively weighting 40\% and 30\%) and three tasks, each of them with $10 \%$ weight in the final grade (TABLE I). These were group tasks (maximum of 3 students). Only in one task (task 1) several resources were used simultaneously (simulation, VISIR and calculus); the other two tasks as well as the written tests were solving exercises and problems in a traditional way.

TABLE I. ASSESSMENT PLAN

\begin{tabular}{|c|c|c|}
\hline Week 3 & $\begin{array}{l}\text { VISIR Introduction by } \\
\text { Teacher }\end{array}$ & \multirow{13}{*}{ 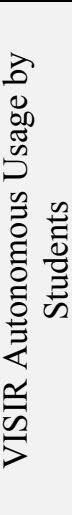 } \\
\hline Week 4 & VISIR Usage in Class & \\
\hline \multicolumn{2}{|l|}{ Week 5} & \\
\hline Week 6 & Written Test_1 & \\
\hline Week 7 & VISIR Tutorial & \\
\hline \multicolumn{2}{|l|}{ Weeks 8-9 } & \\
\hline Week 10 & Deliver Task_1 & \\
\hline \multicolumn{2}{|l|}{ Week 11} & \\
\hline Week 12 & Written Test_2 & \\
\hline \multicolumn{2}{|l|}{ Weeks 13-15 } & \\
\hline Week 16 & Deliver Task_2 & \\
\hline \multicolumn{2}{|l|}{ Week 17} & \\
\hline Week 18 & Deliver Task_3 & \\
\hline
\end{tabular}

Task 1 assessment, consisted on the analysis of one RLC circuit (see Fig. 2), using two different voltage sources.

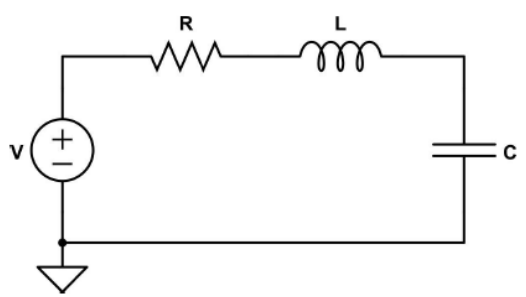

Fig. 2. RLC circuit

Students had to use three different resources - calculus (differential equations, with complex numbers and Laplace transforms and graphical tools), simulation and remote lab VISIR - to calculate the electric current and the voltage drop 
across the inductor (L). Finally, they had to do a report comparing and analyzing the results (using the two voltage sources) obtained with the three resources.

\section{RESEARCH DESIGN}

\section{A. Problematic and research question}

The problematic tackled in this work is related with the use of virtual lab resources in a theoretical calculus course. Since in any engineering degree students' experimental competences and higher order skills are fundamental, the research question addressed is "Which are the advantages of using simultaneous different online lab resources to contextualize a math calculus theoretical course?"

\section{B. Research Design}

A case study methodology will be adopted [21] using a mixed method approach [22] based on the designed course implementation described in the previous sections, which involved 1 teacher and 36 students.

In order to address the research question, several types of data were recorded and cross-analyzed.

\section{Collected Data}

The analyzed data consisted of students' assessment results (as a whole and in each assessment task/test) and their class attendance. Former grades on a similar course were compared to present results.

At the end of the implementation the teacher made available an online students' satisfaction questionnaire (built on a validated set of questions) to enhance the study scope by analyzing students' opinions about VISIR and the applied methodology. The questionnaire included twenty closed questions and two open-answer questions for students to report their perception about VISIR

Finally, the teacher was also asked to fill up a teachers' satisfaction questionnaire, composed by 10 Likert questions, with four options (yes, often, sometimes, no) and a final open question asking for the main advantages/disadvantages of this resource. His opinion was also recorded during a semi-directive interview, via Skype. He shared his experience regarding the design and implementation using VISIR.

As a method of data processing, a descriptive analysis of the students' answers was chosen, which gives a fundamental importance to what the informants report as a mean to capture what they think and believe through their own words. In that sense, the researcher looks for semantic clusters within responses, and therefore quantifies not the number of students, but of the ideas expressed by them, as one person may have pointed more than one argument as regards interest and/or difficulty.

\section{RESUlTS AND DisCUSSION}

\section{A. Tests/Tasks Results}

A total of 30 students (83\%) were assessed, although not all of them in all the tests/tasks and about $64 \%$ of the enrolled students completed the course (final grade equal or higher than
6 , out of 10). There were 6 students who did not fulfill any kind of assessment.

In general, students' performed well. Most of the students achieved a good grade in several tasks/tests (TABLE II), although in written test 1 the average grade was below 6 . Looking at these results per item it is clear that students achieved a better result in task 1: mean grade of 9,1 , with minimum and maximum obtained grades respectively of 6 and 10. Although only 24 students delivered this task, all of them achieved good results and the grades were quite homogeneous (standard deviation of 1,025).

TABLE II. GRADES BY TASK/TEST

\begin{tabular}{|l|c|c|c|c|}
\hline & $\begin{array}{l}\text { Number of } \\
\text { Students }\end{array}$ & $\begin{array}{l}\text { Minimum } \\
\text { Grade }\end{array}$ & $\begin{array}{l}\text { Maximum } \\
\text { Grade }\end{array}$ & $\begin{array}{l}\text { Average } \\
\text { Grade }\end{array}$ \\
\hline Task_1 & 24 & 6,0 & 10,0 & 9,1 \\
\hline Task_2 & 23 & 0,5 & 10,0 & 7,2 \\
\hline Task_3 & 29 & 3,5 & 10,0 & 8,8 \\
\hline Test_1 & 29 & 1,5 & 10,0 & 5,7 \\
\hline Test_2 & 30 & 0,5 & 10,0 & 6,5 \\
\hline Final & 30 & 2,0 & 10,0 & 6,4 \\
\hline
\end{tabular}

As the focus of this work is on the use of several resources, we decided to consider the average grades obtained by this group of students (Group1 - the ones who delivered task 1) and compare it with the average grades obtained by all the class (Group All). As it can be observed in TABLE III, the students who delivered task 1, performed better in all components, with a difference of $7 \%$ in the final grade relatively to all class. Even, being aware that Group 1 may include the most interested/best students, it is clear the use of these several resources improves students' performance.

TABLE III. GRADES BY GROUP

\begin{tabular}{|l|c|c|c|}
\hline & Group All & Group 1 & Difference \\
\hline Task_1 & 9,1 & 9,1 & - \\
\hline Task_2 & 7,2 & 7,4 & 0,2 \\
\hline Task_3 & 8,8 & 9,4 & 0,6 \\
\hline Test_1 & 5,7 & 6,2 & 0,5 \\
\hline Test_2 & 6,5 & 7,1 & 0,6 \\
\hline Final & 6,4 & 7,1 & 0,7 \\
\hline
\end{tabular}

A statistical analysis (with 95\% confidence interval) was performed to assess the significance of the use of virtual resources as well as class attendance in the grades per task/test and final grade. We have used a Pearson correlation, as the variables in study followed a normal distribution [23]. The results are summarized in TABLE IV (the blank spaces mean there is no significant correlation).

TABle IV. PEARson CORRELATION BETWEEN RESOURCES USAGE AND STUDENTS' GRADES

\begin{tabular}{|c|c|c|c|c|c|c|}
\hline & Task_1 & Task_2 & Task_3 & Test_1 & Test_2 & Final \\
\hline Task_1 & 1 & $0.497^{* *}$ & $0.533^{* *}$ & & $0.500^{* *}$ & $0.389^{*}$ \\
\hline $\begin{array}{c}\text { Class } \\
\text { Atend }\end{array}$ & $0.389^{*}$ & $0.350^{*}$ & $0.884^{* *}$ & & $0.366^{*}$ & $0.738^{* *}$ \\
\hline
\end{tabular}

* Correlation is significant at the 0.05 level

** Correlation is significant at the 0.01 level 
It is clear from TABLE IV that there is a significant correlation between the use of several resources and the grades obtained in each task/test, except for test 1 (done before task 1) - still, although VISIR was available to students since the $3^{\text {rd }}$ week and they had been encouraged to use it, its usage was clearly intensified after the tutorial video was made available and the task 1 delivery date getting closer. The same conclusion can be drawn considering class attendance - the most attending students had better results. These results suggest that the use of several resources boost student learning and competences development.

Considering average final grade, there was a gain of $0,3(3 \%)$ compared to previous year, but if we only consider Group 1 (the ones who used several resources) the gain is of $10 \%$.

\section{B. Students Satisfaction Questionnaire}

In order to better understand how students felt about the usage of VISIR and this methodology, it was analyzed the satisfaction questionnaires - 20 students (55\%) answered it. For the sake of this study we choose some relevant questions out of the 20 closed ones: four of them which refer to the students' autonomous work $(1,7,11 \& 19)$ and five which focus on the development of practical, experimental and reflexive skills (3, $5,6,12 \& 14)$. To summarize the results of the first ones, the whole group responded it was not hard to find time to perform the assigned experiments, and, in relation to it, almost everyone (18) declared that they frequently performed experiments due to the possibility to use it $24 / 7$. When asked if they showed VISIR experiments to people outside university, the majority (14) answered negatively. The question about sharing experiment results with their peers showed a more diversified spectrum, although a small majority responds "partially". As regards the development of specific skills, 16 students tried the experiments many times if they thought measures were odd, and the same number of students found the measurement devices easy to use. As a conclusion, it is significant that only 4 students $(20 \%)$ prefer hands-on experiments to remote labs, reinforced by the fact that almost all of them (17) were less afraid of damaging the remote lab system than during hands-on classes. Still, only 7 students think they can manage the remote lab very well (3 fully agree and 4 agree).

As regards the two open-answer questions, they attempt to elicit what the students find as most interesting about the use of the remote laboratory VISIR and which problems they found in using the remote lab. They are important because they allow to expand previous ideas from the predefined questions or to add new ones. For example, one of the few students who answered to prefer hands-on experiment to remote labs adduced in his open answer that The experiments in traditional laboratories are more exciting, in addition to the advantage of being able to ask questions in person to the adviser. The expressions pointed by the UFSC students of Engineering, regarding the most interesting aspects about VISIR, are shown -in their own termsin TABLE $\mathrm{V}$.

As regards problems found in using the remote lab, three answers pointed towards the errors: server error, some persisting error, and an eventual error in the reading on the oscilloscope. On the other hand, what one student summarized as strange results, was referred by 10 students. For example: $I$ did the experiment and worked correctly, I repeated the same experiment but it no longer worked as expected. One student also referred to the difficulty in learning to manipulate, reinforcing what he stated in the corresponding closed question. Finally, 3 students made an explicit statement for no difficulties: nothing, whereas 2 left the question unanswered, meaning -probably, as well - no difficulties.

TABLE V. OPEN ANSWERS

\begin{tabular}{|l|c|}
\hline Ideas & \# of answers \\
\hline real lab resemblance & 5 \\
\hline $\begin{array}{l}\text { the possibility of performing experiments without the need } \\
\text { of a real (physical) laboratory }\end{array}$ & 4 \\
\hline ease of use & 2 \\
\hline practicality & 2 \\
\hline the fact of experimenting in any place and time & 2 \\
\hline the variety of resources and functions & 2 \\
\hline visualization of results & 1 \\
\hline risk avoidance & 1 \\
\hline all over the world & 1 \\
\hline time saving (cutting and unscrewing cables) & 2 \\
\hline the possibility to design circuit as desired & \\
\hline everything & \\
\hline
\end{tabular}

\section{Teacher Perception}

Teacher shared students' work, achievements and final results. He started by filling up a teachers' satisfaction questionnaire to evaluate VISIR remote lab. He considered VISIR was easy to use with a friendly interface and components suitable for his needs. He found the procedures were easy to carry out, so he felt no need to use VISIR manuals as this resource allowed him intuitively to assign experiments, although sometimes he had problems with the server. In the open question he stated that it was a huge advantage to have access to an actual lab during this rather theoretical course of Calculus. The lab served initially as a motivation for the methods and later for their verification in real circuits. Although the performance of the remote lab was unstable at times, it did not prevent students from using it.

The teacher considered that there were 8 students $(22 \%$ of the enrolled students) achieving higher order competences and that VISIR usage largely contributed to it. It means an increase of about $8 \%$ considering the previous academic year, when a traditional methodology was used. It is worth mentioning that although their final grades varied from 7 to 10 , the grade in task 1 varied from 9 to 9,5 and their class attendance was from 32 to 36 (that is, all classes). All, except one of these 8 students, filled up the satisfaction questionnaire.

He thought that VISIR is an excellent resource and he is thinking of increasing its usage in this course (considering also an RC circuit analysis) and using it in another course (Probabilities and Statistics). He acknowledged that VISIR increased students' motivation, their commitment and ultimately their general performance. 
His advice for those who plan to use it, is to give particular attention to students when using VISIR for the first time. Students may experience some difficulties in the beginning, so they need time with the teacher and/or tutorials. In fact, teacher's attention to VISIR plays a crucial role in students' engagement as it was already reported in literature [14], [19].

\section{CONCLUSIONS}

The presented results, although preliminary, support the assumption that the use of several resources (VISIR, simulation, calculus) improves students' performance, helping them to develop higher order skills, such as critical analysis. In fact, Group 1 students (the one who used those resources) achieved better grades in all tasks/tests, with a difference of $7 \%$ in final grade. Plus all the 8 students identified has achieving higher order skills belong to this group. Still the use of VISIR requires time spent with students, in class, explaining and exploring its functionalities. In fact, this introduction to VISIR plays a crucial role in the implementation success, preventing students to get overwhelmed.

Teachers' perception was that students' general performance was good, as they were committed, doing the assignments and attending lectures and that VISIR contributed to increase their motivation and engagement. In fact, accordingly to the teacher, VISIR represented a huge advantage - students can access to a real lab during a rather theoretical calculus course addressing more easily its contextualization into real physical devices.

Finally, answering the research question, the results indicate that students clearly benefit from the usage of several resources, being more motivated and achieving better results. In this case of a math course, this brought important contextualization of the theoretical approaches, which may have helped students to see its pertinence.

\section{ACKNOWLEDGMENT}

The authors would like to acknowledge the support of the VISIR Community, the financial support provided by the European Commission through grant 561735-EPP-1-2015-1PT-EPPKA2-CBHE-JP and to all students who contributed to this work.

This research work is made within the University of Salamanca PhD Program on Education in the Knowledge Society

\section{REFERENCES}

[1] L. D. Feisel and A. J. Rosa, "The Role of the Laboratory in Undergraduate Engineering Education," Journal of Engineering Education, pp. 121-130, January 2005.

[2] C. Jara, F. Candelas, S. Puentes and F. Torres, "Hands-on experiences of undergraduate students in Automatics and Robotics," Computer and Education, 57, pp. 2451-2461, 2011.

[3] I. Gustavsson, G. Alves, C. R., K. Nilsson, J. Zackrisson, U. HernandezJayo and J. Garcia-Zubia, "The VISIR Open Lab Platform 5.0 - an architecture for a federation of remote laboratories," in REV 2011: 8th International Conference on Remote Engineering and Virtual Instrumentation, Brasov, Romania, 2011.

[4] M. Prensky, "Digital Natives, Digital Immigrants," On the Horizon (MCB University Press), October 2001.
[5] J. E. Froyd, P. C. Wankat and K. A. Smith, "Five Major Shifts in 100 Years of Engineering Education," Proceedings of the IEEE, vol. 100, pp. 1344-1360, 2012.

[6] J. R. Brinson, "Learning outcome achievment in non-traditional (virtual and remote) versus traditional (hands-on) laboratories: A review of the empirical reserach," Computers \& Education, vol. 87, pp. 218-237, 2015.

[7] J. E. Corter, J. V. Nickerson, S. Esche, C. Chassapis, S. Im and J. Ma, "Constructing reality: A study of remote, hand-on and simulated laboratories," ACM Transactions on Computer Human Interaction, 14(2), 2007.

[8] J. Corter, S. Esche, C. Chassapis, J. Ma and J. Nickeson, "Process and learning outcomes from remotely-operated, simulated and hands-on student laboratories," Computers \& Education, 57, pp. 2054-2067, 2011.

[9] J. Richardson, "Approaches to studying, conceptions of learning and learning styles in higher education," Learning and Individual Differences, 21, pp. 288-293, 2011.

[10] R. Felder and L. Silverman, "Learning and Teaching Styles in Engineering Education," Engineering Education, 78 (7), pp. 674-681, 1988.

[11] P. A. Kirschner and J. J. Merriënboer, "Do Learner Really Know Best? Urban Legends in Education," Educational Psycologist, vol 48, No 3, pp. 169-183, 2013.

[12] C. Sarabando, J. P. Cravino and A. A. Soares, "Improving Student Understanding of the Concepts of Weight and Mass With a Computer Simulation," Journal of Baltic Science Education, Vol. 15, No. 1, pp. 109-126, 2016.

[13] A. E. Cunha, E. Saraiva, C. A. Santos, F. Dinis and B. Lopes, "Teacher mediation actions and students' productive engagement during the use of computer simulations in physical science classrooms," Procedia Technology, vol. 13, pp. 76-85, 2014.

[14] A. Marques, C. Viegas, C. Costa-Lobo, A. Fidalgo, G. Alves, J. Rocha and I. Gustavsson, "How Remote Labs Impact on Course Outcomes: Various Practises Using VISIR," IEEE-Transactions on Education, 2014.

[15] "[IAOE] Winners of the GOLC Online Laboratory Award," 11 February 2015. [Online]. Available: http://lists.online-lists.org/pipermail/iaoemembers/2015-February/000120.html. [Accessed 2016].

[16] I. Gustavsson and al, "The VISIR Project - An Open Source Software Initiative for Distributed Online Laboratories," in Remote Engineering \& Virtual Instrumentation (REV'07), June 2007.

[17] M. Tawfik, E. Sancristobal, S. Martin, R. Gil, G. Diaz, A. Colmenar, J. Preire, M. Castro, K. Nilsson, J. Zackrisson, L. Hàkansson and I. Gustavsson, "Virtual Instrument Systems in Reality (VISIR) for Remote Wiring and Measurement of Electronic Circuits on Breadboard," IEEE Transactions on Learning Technologies, Vols. Vol 6, No 1, pp. 60-72, 2013.

[18] "UFSC," [Online]. Available: http://structure.ufsc.br/. [Accessed 2 February 2017].

[19] N. Lima, C. Viegas, G. Alves and F. Garcia-Peñalvo, "VISIR's Usage as an Educational Resource: a Review of the Empirical Research," in Proceedings TEEM2016 - Fourth International Conference on Technological Ecosystems for Enhancing Multiculturality (TEEM'16), Salamanca, Spain, 2016.

[20] I. CircuitLab, "CircuitLab," [Online]. Available: https://www.circuitlab.com/. [Accessed 2 February 2017].

[21] L. Cohen, L. Manion and K. Morrison, Research Methods in Education, 6th Edition, London and New York: Routledge, Taylor \& Francis Group, 2007.

[22] J. W. Creswell, Research Design: Qualitative, Quantitative and Mixed Methods Approaches, 4th Edition, SAGE, 2014.

[23] W. J. Conover, Practical nonparametric statistics, New York: John Wiley, 1999. 